\title{
Management of delayed bleeding after endoscopic mucosal resection of large colorectal polyps: a retrospective multi-center cohort study
}

\section{다(1) $(-)$}

\section{Authors}

Simone van der Star ${ }^{1}$, Leon M.G. Moons ${ }^{1}$, Frank ter Borg², Jeroen D. van Bergeijk ${ }^{3}$, Joost M.J. Geesing ${ }^{4}$, John N. Groen ${ }^{5}$, Renske J. Ouwehand ${ }^{1}$, Frank P. Vleggaar ${ }^{1}$, Wouter H. de Vos tot Nederveen Cappel ${ }^{6}$, Frank H.J. Wolfhagen ${ }^{7}$, Matthijs P. Schwartz ${ }^{8}$, Paul Didden ${ }^{1}$

Institutions

1 Department of Gastroenterology and Hepatology, University Medical Center Utrecht, Utrecht, The Netherlands

2 Department of Gastroenterology and Hepatology, Deventer Hospital, Deventer, The Netherlands

3 Department of Gastroenterology and Hepatology, Gelderse Vallei Hospital, Ede, The Netherlands

4 Department of Gastroenterology and Hepatology, Diakonessenhuis, Utrecht, The Netherlands

5 Department of Gastroenterology and Hepatology, Sint Jansdal Hospital, Harderwijk, The Netherlands

6 Department of Gastroenterology and Hepatology, Isala, Zwolle, The Netherlands

7 Department of Gastroenterology and Hepatology, Albert Schweitzer Hospital, Dordrecht, The Netherlands

8 Department of Gastroenterology and Hepatology, Meander Medical Center, Amersfoort, The Netherlands

submitted 22.1.2020

accepted after revision 18.5 .2020

Bibliography

DOI https://doi.org/10.1055/a-1192-3816 |

Endoscopy International Open 2020; 08: E1052-E1060

(c) Georg Thieme Verlag KG Stuttgart · New York eISSN 2196-9736

Corresponding author

P. Didden, MD, PhD, Dept. Gastroenterology \& Hepatology, UMC Utrecht, The Netherlands

Phone: + 31887558175

p.didden@umcutrecht.nl

\# Supplementary material

Online content viewable at:

https://doi.org/10.1055/a-1192-3816

\section{ABSTRACT}

Background and study aims Delayed bleeding (DB) is the most frequent major adverse event after endoscopic mucosal resection (EMR) of large non-pedunculated colorectal polyps (LNPCPs). Evidence-based guidelines for management of DB are lacking. We aimed to evaluate the clinical presentation, treatment and outcome of patients with DB and to determine factors associated with hemostatic therapy.

Patients and methods Patients with DB were identified by analyzing all consecutive EMR procedures for LNPCPs ( $\geq$ $2 \mathrm{~cm}$ ) from one academic center (2012-2017) and seven regional hospitals (2015-2017). DB was defined as any postprocedural bleeding necessitating emergency department presentation, hospitalization or reintervention. Outcome of DB was assessed for three clinical scenarios: continued bleeding $(C B)$, spontaneous resolution without recurrent bleeding during 24 hours observation (SR), and recurrent bleeding (RB). Variables associated with hemostatic therapy were analyzed using logistic regression.

Results DB occurred after 42/542 (7.7\%) EMR procedures and re-colonoscopy was performed in 30 patients (72\%). Re-colonoscopy and hemostatic therapy rates were $92 \%$ and $75 \%$ for $C B(n=24), 25 \%$ and $8 \%$ for $S R(n=12)$, and $83 \%$ and $67 \%$ for $R B(n=6)$, respectively. Frequent hematochezia ( $\geq$ hourly) was the only factor significantly associated with hemostatic therapy ( $R R$ 2.23, $p=0.01$ ). Re-bleeding after endoscopic hemostatic therapy occurred in $3 / 22$ (13.6\%) patients.

Conclusion Ongoing or recurrent hematochezia is associated with a high rate of hemostatic therapy, warranting re-colonoscopy in these patients. A conservative approach is justified when bleeding spontaneously settles, and without recurrent hematochezia during 24 hours observation patients can be safely discharged without endoscopic reexamination. 


\section{Introduction}

Endoscopic mucosal resection (EMR) is the preferred treatment for large ( $\geq 2 \mathrm{~cm}$ ) non-pedunculated colorectal polyps (LNPCPs) $[1,2]$. EMR is a minimally invasive technique which has proven to be safe, efficacious, and cost-effective $[3,4]$.

Delayed bleeding (DB) is the most frequent major adverse event (AE), occurring in 3.7\% to $7 \%$ after colorectal EMR [4-8]. Reported clinical and procedural risk factors include proximal colon location, polyp size $\geq 40 \mathrm{~mm}$, use of anticoagulants, no preventive clipping, age $>75$ years, ASA score $\geq$ III, use of an electrosurgical current not controlled by a microprocessor, and intraprocedural bleeding [5-8]. Remarkably, only limited information is available on the detailed clinical course and management of DB. It has been shown that reintervention is indicated in approximately $35 \%$ to $43 \%$ of DBs, which in the majority is performed by re-colonoscopy $[6,7,9]$. However, identification of patients who require an endoscopic hemostatic intervention has not been fully elucidated $[5,7,10]$. As a consequence, there is a need for clinical tools that can assist in deciding whether re-colonoscopy should be pursued or a conservative approach suffices. Until now, only one study has looked into post-EMR DBs in more detail, evaluating the clinical course and management of 62 cases [9].

The aim of our study was to evaluate management of DB for different clinical scenarios and to examine clinical factors associated with the application of hemostatic therapy in a large multicenter cohort of patients with post-EMR DB.

\section{Patients and methods \\ Study design and population}

This was a retrospective analysis of a multicenter cohort of patients who underwent EMR for large $(\geq 2 \mathrm{~cm})$ non-pedunculated colorectal polyps (LNPCPs). Patients were extracted from the OPTICAL study, in which LNPCPs of consecutive patients from eight hospitals (seven non-academic and one academic hospital) were prospectively registered between September 2015 and December 2016 [11]. In addition, patients were collected from a prospective registry of consecutive patients who underwent colorectal EMR in the same academic hospital between March 2012 and October 2017. Patients with DB were identified by evaluating patient files up to 1 month after the EMR procedure. DB was defined as: "any bleeding occurring after the completion of the procedure, necessitating emergency department presentation, hospitalization or re-intervention (repeat endoscopy, angiography, or surgery)" [5]. Self-limited bleeding that did not require medical care or managed on an outpatient basis was not deemed clinically significant.

This study was approved by the Medical Research Ethics Committee of University Medical Center Utrecht (reference number 17/517) and was carried out in accordance with the Helsinki Declaration.

\section{Outcomes and data collection}

The primary aim was to assess management of all patients with DB, when classified into three clinical scenarios. A secondary aim was to determine clinical factors associated with use of hemostatic therapy. Use of hemostatic therapy was defined as undergoing any intervention at endoscopy, radiography or surgery to manage bleeding. Conservative treatment and undergoing colonoscopy without endoscopic intervention were defined as no hemostatic therapy. Other secondary outcomes were to identify factors associated with active bleeding seen at the post-EMR site, and to determine risk factors for DB.

Medical records and endoscopy reports of all patients were reviewed. Detailed information about clinical course and management of DB were collected. Patients were classified into three different clinical scenarios which were distinguished based on the initial course of DB: 1. continued bleeding (CB), defined as ongoing hematochezia for at most 24 hours after onset, irrespective of frequency; 2. spontaneous resolution (SR), without recurrent bleeding during a 24-hour observation period with either hemodynamic stability or a stable hemoglobin level (not both) as a prerequisite for discharge; or 3. recurrent bleeding (RB), defined as re-occurrence of hematochezia after a period of at least 6 hours without rectal blood loss. These clinical scenarios have been suggested to be clinically relevant in a previously published algorithm and were also thought to be valuable in our own experience [9]. Furthermore, data on time of onset of bleeding, presence of hemodynamic stability, frequency of hematochezia, hemoglobin levels at presentation, fluid resuscitation, transfusion requirements, findings at re-colonoscopy, rate of recurrent DB, and duration of hospitalization were noted. Onset of bleeding was defined as the moment of presentation at the emergency department. In most cases, EMR was followed by 12 to 24 hours of inpatient observation. In case of DB during inpatient observation, days of admission were counted from the day of onset of bleeding. Hemodynamic instability was defined as heart rate $\geq 100 \mathrm{bpm}$ or systolic blood pressure $\leq 100 \mathrm{mmHg}$. Active bleeding was defined as spurting or oozing hemorrhage witnessed during re-colonoscopy. Endoscopic hemostatic therapy included any modality with the intention to achieve hemostasis or reduce rebleeding, usually by application of clips, adrenaline injection and/or coagulation therapy (bipolar hemostasis catheter or coagulation forceps). Re-bleeding was defined as DB occurring after hemostatic therapy or after discharge. All aspects of management of DB, including initial treatment, indication for re-colonoscopy and (type of) hemostatic therapy, were left to treating physician.

The following data were extracted of all patients, divided into patient characteristics (age, gender, ASA score, comorbidity and use of anticoagulants), polyp characteristics (size, location, Paris classification and histology) and procedural factors (submucosal lifting-sign, use of adrenaline in submucosal injection, macroscopic complete resection, prophylactic clip closure and intraprocedural bleeding, defined as any bleeding occurring during the procedure necessitating direct hemostatic therapy). Prophylactic clip closure was defined as placement of at least one clip (not always leading to complete closure) with 
the intention to reduce the risk of delayed bleeding and/or perforation. Incomplete resection was defined as macroscopic residual polyp tissue after adjunctive treatment.

\section{Description of EMR procedure}

All EMR procedures were performed by an experienced endoscopist (>100 EMRs) or a senior therapeutic endoscopy fellow under their direct supervision. EMR was performed using the injection-assisted technique with snare electrocautery, as previously described [12]. Whether the EMR site was prophylactically closed with clips was left to the endoscopist's discretion. Patients were either discharged after four hours postprocedural recovery or were admitted for one-night observation. Regarding the use of antithrombotic therapy, only aspirin was allowed to be continued during the procedure. In case of another or double antiplatelet agents, the non-aspirin drug was replaced by aspirin or ceased 7 days before the procedure (aspirin continued), respectively. Anticoagulant agents were ceased 3 to 5 days before the procedure. Bridging therapy was used in patients with high thrombotic risk, according to local guidelines. In most cases, antiplatelet and anticoagulant agents were recommenced one day after the procedure. Synchronous small polyps $(<20 \mathrm{~mm})$ or large $(\geq 20 \mathrm{~mm})$ pedunculated polyps were usually resected during the same procedure, albeit the decision was at the discretion of the endoscopist.

\section{Data analysis}

Baseline characteristics of all patients and subjects with DB were analyzed using descriptive statistics. If a patient had two or more polyps resected and the bleeding site was unknown, one polyp was selected at random for analysis. Clinical outcome, management, and use of hemostatic therapy were reported for the three different clinical scenarios.

Multivariable logistic regression analysis with backward stepwise selection was performed to identify factors, including patient-, polyp- and clinical characteristics, associated with use of hemostatic therapy in patients with DB. All variables were checked for collinearity using Pearson's test. Factors with a $P$ value for association of $\leq 0.2$ were incorporated in the final multivariable regression analysis. Due to the high rate of events, relative risks were calculated for statistically significant factors.

Similar analysis was performed for active bleeding witnessed during re-colonoscopy. In addition, risk factors for DB were determined using logistic regression analysis in the entire EMR cohort. Factors with $P<0.2$ in the univariable analysis were considered for multivariable analysis. Analysis was performed using IBM SPSS statistical software, version 24. $P<0.05$ were regarded as statistically significant.

\section{Results}

A total of 542 LNPCPs were removed during 482 endoscopic procedures conducted in 469 patients. Forty-seven patients had more than one LNPCP removed during the same procedure: two polyps $(n=36)$, three polyps $(n=9)$, four polyps $(n=1)$, five polyps $(n=1)$. The majority of LNPCPs $(57.2 \%)$ were located in the distal colon. Twenty-seven resections (5.0\%) were incom- plete, of whom five patients underwent surgery. Baseline characteristics of patients and LNPCPs are shown in $>$ Table 1 . Synchronous small polyps were resected in $37.1 \%$ (179/482) of the procedures (median number 2 [range 1-19], median size $6 \mathrm{~mm}$ [1-19 mm]). Large ( $\geq 20 \mathrm{~mm})$ pedunculated polyps were removed during 26 procedures (5.4\%) (median number 1 [1-4]), median size $25 \mathrm{~mm}$ [20-60 mm]).

\section{Characteristics of DB and risk factors}

DB occurred in 42 patients $(8.7 \%$ and $7.7 \%$ based on the number of endoscopic procedures and LNPCPs, respectively) ( $\triangleright \mathrm{Ta}$ ble 1 ), including 10 patients in whom two or more LNPCPs were removed during the same procedure. Multivariable regression analysis showed that both platelet aggregation inhibitors (OR $2.86(95 \% \mathrm{Cl} 1.3-6.26), P=0.009)$ and anticoagulants (OR 4.72 (95\% Cl 2.12-10.53), $P<0.01$ ) use within 7 days after the procedure, and increasing polyp size (OR 1.19 (95\% Cl 1.011.41), $P=0.04$ ) were independent risk factors for DB (Supplementary Table 1). A trend towards a higher DB risk was observed for proximal location (OR 1.9 (95\% Cl 0.98-3.66), $P=$ $0.057)$. Concurrent polypectomy of small or pedunculated polyps was not a risk factor for DB.

The majority of DBs occurred within 72 hours after EMR ( $n=$ $25,59.5 \%)$. Clinical parameters and management at presentation are shown in $>$ Table 2 . Frequent hematochezia ( $\geq$ hourly) was observed in 13 patients $(31.0 \%)$ and in only one patient hemodynamic instability could not be restored by fluid resuscitation, requiring intensive care unit admission. Median duration of hospitalization was 2 days (interquartile range $1-3$ ). The majority of patients with DB ( $n=19,45 \%)$ were included from an academic hospital (Supplementary Table 2).

\section{Management for different clinical scenarios}

The most common clinical scenario of DB was continued bleeding $(n=24,57.1 \%)$. DB settled spontaneously in the remaining 18 patients $(42.9 \%)$, of whom six developed recurrent bleeding, but the majority $(n=12)$ had persistent hemostasis during 24-hour observation.

The flowchart of all patients with DB categorized into three distinct clinical scenarios is shown in $>$ Fig. 1. Re-colonoscopy was performed in 30 patients (71.4\%) and was most frequently performed in the CB-group (22/24, $92 \%)$, followed by the RBgroup (5/6, 83\%) and SR-group (3/12, $25 \%)$. Endoscopic findings during re-colonoscopy are shown in $>$ Table 3 . Active bleeding $(n=6)$ or stigmata of recent bleeding $(n=18)$ were found in the majority (88.9\%) of patients with CB or RB. Twenty-two of 30 patients received hemostatic therapy during the first re-colonoscopy ( $\mathbf{F i g . 2}$ ). Hemostatic therapy rates were $18 / 24(75 \%)$ in the CB-group and 4/6 (67\%) in the RB-group. In the SR-group, only one of the 12 patients ( $8 \%$ ) underwent hemostatic therapy, this was at a second re-colonoscopy due to a late recurrent bleeding. The clinical outcome of the remaining 11 patients was favorable without readmission or recurrent bleeding.

Endoscopic hemostatic therapy included only clips $(n=14)$, only coagulation $(n=2)$, adrenaline and coagulation $(n=2)$, adrenaline and clips $(n=2)$, coagulation and clips $(n=1)$ and 
- Table 1 Baseline characteristics of all LNPCPs and subjects with DB.

\begin{tabular}{|c|c|c|}
\hline & $\begin{array}{l}\text { All LNPCPs } \\
\mathrm{n}=542\end{array}$ & $\begin{array}{l}\text { DB } \\
n=42\end{array}$ \\
\hline \multicolumn{3}{|l|}{ Patient characteristics } \\
\hline " Age, years, mean (range) & $68.3(38-90)$ & $69.4(58-87)$ \\
\hline \multicolumn{3}{|l|}{ Gender, n (\%) } \\
\hline - Male & $330(60.9)$ & $31(73.8)$ \\
\hline - Female & $212(39.1)$ & $11(26.2)$ \\
\hline \multicolumn{3}{|l|}{ ASA grade, $n$ (\%) } \\
\hline - 1 & $185(34.1)$ & $5(11.9)$ \\
\hline .2 & $261(48.2)$ & $25(59.5)$ \\
\hline - 3 or 4 & $96(17.7)$ & $12(28.5)$ \\
\hline \multicolumn{3}{|l|}{ Comorbidity conditions ${ }^{1}, \mathrm{n}(\%)$} \\
\hline - None & $211(38.9)$ & $8(19.0)$ \\
\hline - Cardiovascular & $280(51.7)$ & $30(71.4)$ \\
\hline - Pulmonary & $105(19.4)$ & $11(26.2)$ \\
\hline - Renal & $43(7.9)$ & $6(14.3)$ \\
\hline \multicolumn{3}{|c|}{ Continued antithrombotic drugs, n (\%) } \\
\hline - None & $450(83.0)$ & $30(71.4)$ \\
\hline $\begin{array}{l}\text { - Platelet aggregation } \\
\text { inhibitors }{ }^{2}\end{array}$ & $90(16.6)$ & $12(28.6)$ \\
\hline - Anticoagulation ${ }^{3}$ & $2(0.4)$ & - \\
\hline \multicolumn{3}{|c|}{$\begin{array}{l}\text { Use of antithrombotic drugs within seven days after the proce- } \\
\text { dure, } n(\%)\end{array}$} \\
\hline - None & $372(68.6)$ & $17(40.5)$ \\
\hline $\begin{array}{l}\text { - Platelet aggregation } \\
\text { inhibitors }{ }^{2}\end{array}$ & $99(18.3)$ & $12(29.5)$ \\
\hline - Anticoagulation ${ }^{3}$ & $71(13.1)$ & $13(31.0)$ \\
\hline \multicolumn{3}{|l|}{ Polyp characteristics } \\
\hline - Lesion size, cm, mean (SD) & $3.6(1.7)$ & $4.1(1.8)$ \\
\hline \multicolumn{3}{|l|}{ Lesion location, n (\%) } \\
\hline - Rectum & $67(12.4)$ & $5(11.9)$ \\
\hline - Rectum $<2 \mathrm{~cm}$ dentate line & $25(4.6)$ & $6(14.3)$ \\
\hline - Rectosigmoid & $12(2.2)$ & - \\
\hline - Sigmoid & $52(9.6)$ & $2(4.5)$ \\
\hline - Descending colon & $21(3.9)$ & - \\
\hline - Splenic flexure & $14(2.6)$ & - \\
\hline - Transverse colon & $58(10.7)$ & $4(9.5)$ \\
\hline - Hepatic flexure & $61(11.3)$ & $2(4.8)$ \\
\hline - Ascending colon & $110(20.3)$ & $8(19.0)$ \\
\hline - Cecum & $78(14.4)$ & $10(23.8)$ \\
\hline - Cecum appendix involved & $11(2.0)$ & - \\
\hline
\end{tabular}

Table 1 (Continuation)

\begin{tabular}{|c|c|c|}
\hline & $\begin{array}{l}\text { All LNPCPs } \\
n=542\end{array}$ & $\begin{array}{l}\text { DB } \\
n=42\end{array}$ \\
\hline $\begin{array}{l}\text { - Cecum ileocecal valve } \\
\text { involved }\end{array}$ & $33(6.1)$ & $5(11.9)$ \\
\hline - Distal location ${ }^{4}$ & $310(57.2)$ & $19(45.2)$ \\
\hline - Proximal location ${ }^{5}$ & $232(42.8)$ & $23(54.8)$ \\
\hline \multicolumn{3}{|l|}{ Paris classification, n (\%) } \\
\hline . Is & $184(33.9)$ & $5(11.9)$ \\
\hline - Ila & $201(37.1)$ & $21(50.0)$ \\
\hline - IIb & $7(1.3)$ & $1(2.4)$ \\
\hline - IIc & - & - \\
\hline - III & - & - \\
\hline - Ila+Ilc & $13(2.4)$ & - \\
\hline - Ila +Is & $61(11.3)$ & $7(16.7)$ \\
\hline - Isp & $10(1.8)$ & $1(2.4)$ \\
\hline - Unknown & $66(12.2)$ & $7(16.7)$ \\
\hline \multicolumn{3}{|l|}{ Status of EMR, $n$ (\%) } \\
\hline - First EMR & $505(93.2)$ & $37(88.1)$ \\
\hline - Residual/recurrence & $37(6.8)$ & $5(11.9)$ \\
\hline \multicolumn{3}{|l|}{ Resection, n (\%) } \\
\hline - Piecemeal & $494(91.1)$ & $40(95.2)$ \\
\hline - En bloc & $45(8.3)$ & $2(4.8)$ \\
\hline - Unknown & $3(0.6)$ & - \\
\hline \multicolumn{3}{|l|}{ Success of resection, n (\%) } \\
\hline - Complete & $515(95.0)$ & $40(95.2)$ \\
\hline - Incomplete & $27(5.0)$ & $2(4.8)$ \\
\hline \multicolumn{3}{|l|}{ - Prophylactic clip closure, n (\%) } \\
\hline - Yes & $463(85.4)$ & 39 (92.9) \\
\hline . No & $79(14.6)$ & $3(7.1)$ \\
\hline \multicolumn{3}{|l|}{ Histology } \\
\hline \multicolumn{3}{|l|}{ Polyp histology, n (\%) } \\
\hline - Tubular adenoma & $135(24.9)$ & $11(26.2)$ \\
\hline - Tubulovillous adenoma & $257(47.4)$ & $24(57.1)$ \\
\hline - Villous adenoma & $64(11.8)$ & $2(4.8)$ \\
\hline - Serrated adenoma & $55(10.1)$ & $3(7.1)$ \\
\hline - Submucosal invasive cancer & $27(5.0)$ & $2(4.8)$ \\
\hline - Lipoma & $1(0.2)$ & - \\
\hline - Not available & $3(0.6)$ & - \\
\hline \multicolumn{3}{|l|}{ Dysplasia/cancer, n (\%) } \\
\hline - Low-grade dysplasia & 395 (72.9) & $32(76.2)$ \\
\hline
\end{tabular}




\begin{tabular}{|c|c|c|}
\hline \multicolumn{3}{|l|}{ > Table 2 (Continuation) } \\
\hline & $\begin{array}{l}\text { All LNPCPs } \\
n=542\end{array}$ & $\begin{array}{l}\text { DB } \\
n=42\end{array}$ \\
\hline $\begin{array}{l}\text { - Low-grade, focal high-grade } \\
\text { dysplasia }\end{array}$ & $34(6.3)$ & $2(4.8)$ \\
\hline - High-grade dysplasia & $58(10.7)$ & $6(14.3)$ \\
\hline - Submucosal invasive cancer & $27(5.0)$ & $2(4.8)$ \\
\hline - None & $25(4.6)$ & - \\
\hline - Not available & $3(0.6)$ & - \\
\hline $\begin{array}{l}1 \text { Sum of percentages is greater thar } \\
\text { comorbidities } \\
{ }^{2} \text { Including aspirin, clopidogrel, dipy } \\
\text { drugs } \\
{ }^{3} \text { Including acenocoumarol, fenproc } \\
\text { heparin } \\
{ }^{4} \text { Including rectum, sigmoid, descen } \\
\text { colon and hepatic flexure } \\
{ }^{5} \text { Including cecum and ascending co }\end{array}$ & $\begin{array}{l}0 \text { because som } \\
\text { nidole or a con } \\
\text { non, New Oral } \\
\text { colon, splen }\end{array}$ & $\begin{array}{l}\text { nts had severa } \\
\text { g of these } \\
\text { gulants or } \\
\text { e, transverse }\end{array}$ \\
\hline
\end{tabular}

adrenaline, coagulation and clips $(n=1)$. The rate of rebleeding after endoscopic hemostatic therapy for DB was low, occurring in only three patients (13.6\%). Median duration of hospitalization of the SR-, RB- and CB-group was 1.5, 3.0 and 2.5 days, respectively.

\section{Factors associated with use of hemostatic therapy}

Hemostatic therapy was applied in 22 patients (52.4\%) during the first re-colonoscopy. At regression analysis, only frequent hematochezia ( $\geq$ hourly) was associated with use of hemostatic therapy (relative risk 2.23, $P=0.011)(\triangleright$ Table 4$)$. No significant associations were found for other patient, polyp, and clinical characteristics, including hemodynamic instability and hemoglobin level. Need of transfusion and ASA score were excluded from analysis due to significant collinearity with hemoglobin level and resumption of antithrombotic drugs, respectively. Also, no no significant differences were found between the groups with $(n=6)$ and without active bleeding $(n=24)$.

\section{Discussion}

DB is the most common major AE after EMR of LNPCPs, frequently leading to hospitalization and repeated endoscopic examinations. The results of our study show that re-colonoscopy should be strongly considered in patients with $C B$ or RB, particularly in case of frequent hematochezia (hourly or more) as this increases the likelihood of performing hemostatic therapy. On the other hand, re-colonoscopy can be safely omitted when bleeding spontaneously settles because only $8 \%$ received hemostatic therapy during follow-up.

It is still difficult to identify patients with DB who require recolonoscopy. Because the source of bleeding in post-EMR DB is already known, re-colonoscopy is only required to secure hemostasis or prevent re-bleeding. To our knowledge, this is only the second study providing detailed information on a large cohort of post-EMR DBs. A previous study developed a risk strati-
- Table 2 Clinical parameters and management at presentation of patients with delayed bleeding.

\begin{tabular}{|c|c|}
\hline & $\begin{array}{l}\text { DB } \\
n=42\end{array}$ \\
\hline \multicolumn{2}{|l|}{ Onset of bleeding, $n$ (\%) } \\
\hline . $<24$ hours & $20(47.6)$ \\
\hline - 24-72 hours & $5(11.9)$ \\
\hline . 72 hours-7 days & $10(23.8)$ \\
\hline - 8-14 days & $7(16.7)$ \\
\hline \multicolumn{2}{|c|}{ Clinical course after presentation, $n$ (\%) } \\
\hline - Hospital admission & $40(95.2)$ \\
\hline - Discharge & $2(4.8)$ \\
\hline \multicolumn{2}{|c|}{ Frequency of hematochezia, $n(\%)$} \\
\hline " <hourly & $29(69.0)$ \\
\hline - $\geq$ hourly & $13(31.0)$ \\
\hline \multicolumn{2}{|c|}{ Hemodynamic stability, n (\%) } \\
\hline - Stable & $31(73.8)$ \\
\hline - Unstable & $11(26.2)$ \\
\hline \multicolumn{2}{|c|}{ Successful resuscitation with intravenous fluids, $\mathbf{n}$} \\
\hline - Yes & 10 \\
\hline - No & 1 \\
\hline \multicolumn{2}{|l|}{ Blood transfusion, $n$ (\%) } \\
\hline - No & $32(76.2)$ \\
\hline - Yes & $10(23.8)$ \\
\hline
\end{tabular}

fication by assessing the detailed clinical course and management of 62 DBs after wide-field colorectal EMR [9]. Also, a management algorithm is proposed based on their findings and consensus expert clinical opinion, and emphasizes the importance of ongoing or recurrent hematochezia as incentive for performing re-colonoscopy. In our study we were able to distinguish three different clinical scenarios based on the persistence of hematochezia after onset of bleeding. The highest rate of hemostatic therapy was seen in patients with CB and RB (75\% and $66.7 \%$, respectively). The majority of re-colonoscopies performed in these patients revealed post-EMR ulcer findings with anticipated high risk of persistent bleeding or rebleeding, including $22 \%$ with witnessed active bleeding and $59 \%$ with a visible vessel or adherent clot. Although evidence-based recommendations are lacking, it is reasonable to believe that, as with gastrointestinal ulcer bleeding, an advantage of hemostatic therapy can be expected in the presence of these high-risk features. The importance of monitoring rectal blood loss is also emphasized by our finding that hematochezia occurring more than hourly was the only clinical parameter associated with hemostatic therapy. In contrast to the previous study, no association was found for blood transfusion [9]. Our cohort in- 


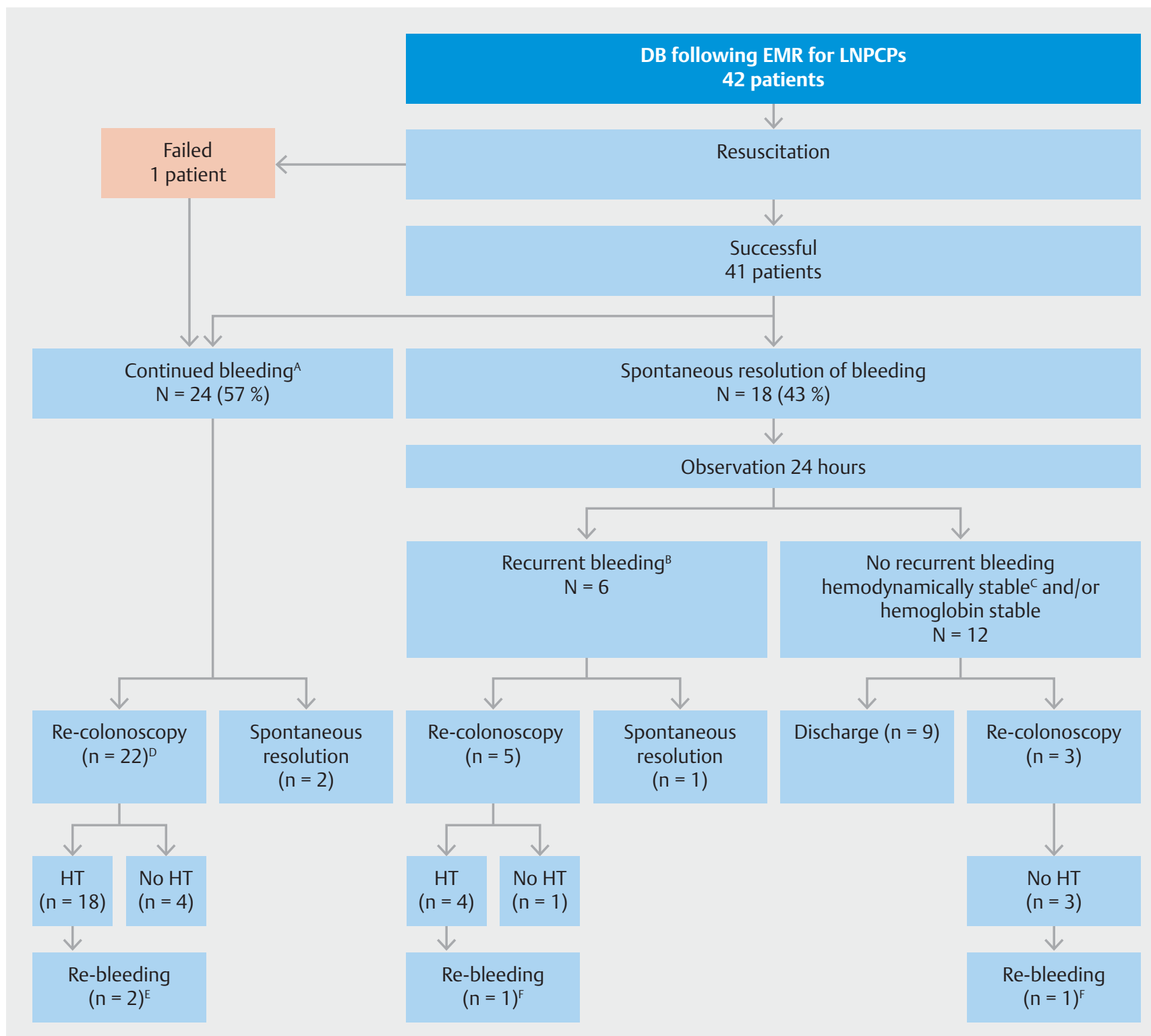

- Fig. 1 Management of 42 patients with DB after EMR for LNPCPs for different clinical scenarios. LNPCP, large non-pedunculated colorectal polyp; HT, hemostatic therapy. A Ongoing hematochezia for at most 24 hours after onset, irrespective of frequency. B Recurrence of hematochezia after a period of at least 6 hours without rectal blood loss. C Heart rate $<100 \mathrm{bpm}$ or systolic blood pressure $>100 \mathrm{mmHg}$. $\mathbf{D}$ Re-colonoscopy performed $\leq 24$ hours, except in one patient who underwent re-colonoscopy 8 days after onset of bleeding. E One patient underwent radiographic embolization and one patient was treated conservatively. $\mathbf{F}$ Hemostatic therapy during second re-colonoscopy.

cluded patients with more severe comorbidity (ASA score $\geq 2$ $88 \%$ vs. $54 \%$ ), elevating the threshold hemoglobin value for blood transfusion $[13,14]$. Surprisingly, hemodynamic instability did not increase the application of hemostatic therapy. Because almost all patients presenting with hemodynamic instability were successfully resuscitated, it is likely that a severe, large-volume bleed has discontinued or significantly diminished, reducing the need for hemostatic intervention. Therefore, we believe that re-colonoscopy should be restricted to patients with frequent ongoing or recurrent hematochezia, because they will likely benefit most from performing hemostatic intervention if considered appropriate.
Clinical tools to determine which patients do not require hemostatic intervention are helpful in preventing unnecessary recolonoscopies and shortening hospital stay. Previous studies suggest that approximately half of DBs after EMR of large colorectal polyps $(\geq 2 \mathrm{~cm})$ are self-limiting. Re-colonoscopies rates for DB range between $38 \%$ and $75 \%[6,7,9,15,16]$, however, data on patients actually receiving hemostatic intervention are limited. Only two studies described management in more detail $[9,16]$, respectively $50 \%$ and $61 \%$ of patients did not undergo any type of hemostatic intervention, which is in line with our findings. Our results indicate that spontaneous discontinuation of hematochezia appears to be the most relevant clinical 


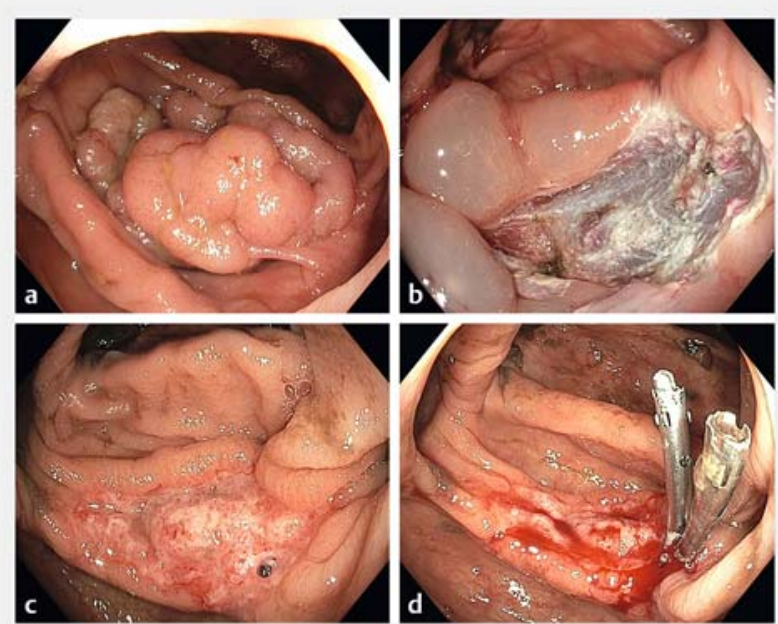

- Fig. 2 a A 30-mm granular Paris 0-Ila + Is polyp, Hiroshima B, in the ascending colon. $\mathbf{b}$ Completely resected by piecemeal EMR, some prominent submucosal vessels are seen after resection. c DB occurred after 8 days with continued bleeding necessitating re-colonoscopy. A visible vessel was seen, without active bleeding. d Hemostatic therapy was used with two hemoclips.

parameter for an indolent course. The majority will not develop recurrent bleeding, even in the long term. It would be of additional benefit to distinguish patients with a high risk of recurrent bleeding, but such a clinical prediction model has not yet been developed for post-EMR DBs. Unfortunately, our study lacks sufficient power to allow solid risk stratification. Recently, the Oakland scoring system has been developed for patients with acute lower gastrointestinal bleeding, incorporating several patient characteristics and clinical parameters at presentation [17]. This model is useful to discriminate patients who can be safely discharged and is able to predict recurrent bleeding. However, performance was demonstrated in an unselected population with post-polypectomy bleedings accounting for only $2 \%$ of the included patients, which calls into question its applicability in post-EMR DBs. In our DB cohort patients with a low risk score (up to 8), which has been associated with a safe discharge, were absent, and another threshold could not be identified (Supplementary Table 3). Although further testing of this model is required in a larger cohort of post-EMR DB, our results suggest that the impact in clinical practice for this specific category of lower gastrointestinal bleeding is probably limited. Therefore, for now, we would advocate a wait-and-see approach if hematochezia resolves spontaneously. It seems safe to discharge these patients after a 24-hour observation period.

One of our secondary outcomes was to identify risk factors for DB. The association of increasing polyp size and antithrombotic drug therapy with $\mathrm{DB}$ is consistent with previous studies $[6-8,18]$. In the majority of studies also proximal location is marked as a significant risk factor for DB [5-8]. Remarkably, we were not able to detect a significant association, however, a trend was observed when excluding the transverse colon and hepatic flexure from proximal location. Importantly, we believe our results are valid because risk estimates have been adjusted for potential confounders such as prophylactic clip closure.

Several limitations of our study should be mentioned. The main limitation is the small number of DB events, which undermines the validity of our study results. As a consequence, only (strongly) associated factors could be identified rather than the measure of association. Second, we used application of hemostatic therapy as one of our major outcomes, although it remains unclear whether this was truly indicated in our patients. As already mentioned, a validated risk score to estimate rebleeding risk based on endoscopically assessed post-EMR ulcer bleeding stigmata is lacking. Consequently, it is still unclear which ulcers will benefit from hemostatic therapy. However,

\begin{tabular}{|c|c|c|c|c|c|c|c|}
\hline \multirow[b]{2}{*}{ Endoscopic findings } & \multirow{2}{*}{$\begin{array}{l}\text { Total } \\
\text { n (\%) }\end{array}$} & \multicolumn{3}{|c|}{ Clinical scenarios } & \multicolumn{3}{|c|}{ Hemostatic therapy } \\
\hline & & CB & RB & SR & HT & Untreated & \% HT \\
\hline \multicolumn{8}{|l|}{ Active bleeding } \\
\hline - Spurting hemorrhage & $4(13.3)$ & 4 & 0 & 0 & 4 & - & 100 \\
\hline - Oozing hemorrhage & $2(6.7)$ & 1 & 1 & 0 & 2 & - & 100 \\
\hline \multicolumn{8}{|l|}{ Stigmata of recent bleeding } \\
\hline - Visible vessel & $8(26.7)$ & 6 & 1 & 1 & 7 & 1 & 87.5 \\
\hline - Adherent clot & $10(33.3)$ & 8 & 1 & 1 & 7 & 3 & 70.0 \\
\hline - Hematin on ulcer base & $2(6.7)$ & 1 & 1 & 0 & 2 & - & 100 \\
\hline \multicolumn{8}{|l|}{ No stigmata of recent bleeding } \\
\hline - Clean ulcer base & $1(3.3)$ & - & 0 & 1 & - & 1 & 0 \\
\hline - Ulcer not found/ visualization not possible & $3(10.0)$ & 2 & 1 & 0 & - & 3 & 0 \\
\hline - Total & 30 & 22 & 5 & 3 & $22(73 \%)$ & $8(27 \%)$ & \\
\hline
\end{tabular}

HT, hemostatic therapy; CB, continued bleeding; RB, recurrent bleeding after spontaneous resolution; SR, spontaneous resolution without recurrent bleeding. 
- Table 4 Multivariable regression analysis to identify factors associated with use of hemostatic therapy

\begin{tabular}{|c|c|c|c|c|}
\hline & $\begin{array}{l}\text { No hemostatic therapy } \\
n=20\end{array}$ & $\begin{array}{l}\text { Hemostatic therapy } \\
n=22\end{array}$ & P value & Relative risk \\
\hline \multicolumn{5}{|l|}{ Patient characteristics } \\
\hline Mean age, years (range) & $69.5(58-83)$ & $69.3(61-87)$ & & \\
\hline \multicolumn{3}{|l|}{ Gender, $\mathbf{n}(\%)$} & & \\
\hline - Female & $4(36.4)$ & $7(63.6)$ & & \\
\hline - Male & $16(51.6)$ & $15(48.4)$ & & \\
\hline \multicolumn{3}{|c|}{ Use of antithrombotic drugs within seven days after the procedure, $\mathbf{n}(\%)$} & & \\
\hline - None & $7(41.2)$ & $10(58.8)$ & & \\
\hline - Platelet aggregation inhibitors & $7(58.3)$ & $5(41.7)$ & & \\
\hline - Anticoagulation & $6(46.2)$ & $7(53.8)$ & & \\
\hline \multicolumn{5}{|l|}{ Polyp characteristics } \\
\hline Increasing lesion size ${ }^{1}$, per cm, mean (SD) & $3.85(1.79)$ & $4.25(1.79)$ & & \\
\hline \multicolumn{3}{|l|}{ Lesion location, $\mathbf{n}(\%)$} & & \\
\hline - Distal location ${ }^{1}$ & $9(47.4)$ & $10(52.6)$ & & \\
\hline - Proximal location ${ }^{2}$ & $11(47.8)$ & $12(52.2)$ & & \\
\hline \multicolumn{5}{|l|}{ Procedural characteristics } \\
\hline \multicolumn{3}{|l|}{ Prophylactic clip closure after EMR, n (\%) } & & \\
\hline - Yes & $3(75.0)$ & $1(25.0)$ & & \\
\hline - No & $17(44.7)$ & $21(55.3)$ & & \\
\hline \multicolumn{5}{|l|}{ Clinical characteristics } \\
\hline \multicolumn{3}{|l|}{ Frequency of hematochezia, $n(\%)$} & \multirow[t]{3}{*}{0.011} & \multirow{3}{*}{$\begin{array}{l}\text { Reference } \\
2.23\end{array}$} \\
\hline . <hourly & $18(62.1)$ & $11(37.9)$ & & \\
\hline - $\geq$ hourly & $2(15.4)$ & $11(84.6)$ & & \\
\hline \multicolumn{3}{|l|}{ Hemodynamic stability, n (\%) } & & \\
\hline - Stable & $15(48.4)$ & $16(51.6)$ & & \\
\hline - Unstable & $5(45.5)$ & $6(54.5)$ & & \\
\hline Mean hemoglobin level at presentation, g/dL (SD) & $12.1(2.3)$ & $12.0(2.0)$ & & \\
\hline
\end{tabular}

we believe that our data are representative of current clinical practice. If the Forrest classification would be applied to the post-EMR ulcers [19], $83.3 \%$ of the patients (20/24) with highrisk endoscopic stigmata (i. e. la, Ib, Ila and IIb) received hemostatic therapy and only two patients underwent endoscopic treatment for low-risk stigmata (i.e. IIc and III). It should be stressed that endoscopic hemostatic technique was not standardized and, although clips were most commonly applied, treatment varied widely. Clear recommendations for optimal endoscopic treatment, therefore, cannot be provided, also due to the low number of rebleeding events after hemostatic treatment. Another limitation is that data used for regression analysis were collected at the moment of presentation at the emergency room or in hospital. Because re-colonoscopy was usually not performed directly after presentation, its findings may not accurately reflect the recorded clinical variables. Finally, our study outcomes should not be generalized to patients suffering from DB after cold snare polypectomy or EMR for small colorectal polyps (<20 mm).

\section{Conclusion}

In conclusion, our study demonstrates that in patients with DB after EMR for LNPCPs the persistence and frequency of hematochezia should be the determining factors in deciding whether to perform re-colonoscopy. Endoscopic re-examination should only be pursued in case of continued or recurrent bleeding, especially in the presence of frequent hematochezia ( $\geq$ hourly), 
as it increases the likelihood of performing hemostatic therapy. If patients have no signs of persistent bleeding after resuscitation, they can be discharged safely after a short observation period without the need for re-colonoscopy.

Competing interests

Leon Moons: Consultancy Boston Scientific, Frank Vleggaar: Consultancy Boston Scientific

\section{References}

[1] Ferlitsch M, Moss A, Hassan C et al. Colorectal polypectomy and endoscopic mucosal resection (EMR): European Society of Gastrointestinal Endoscopy (ESGE) Clinical Guideline. Endoscopy 2017; 49: 270-297

[2] Moss A, Bourke M], Williams SJ et al. Endoscopic mucosal resection outcomes and prediction of submucosal cancer from advanced colonic mucosal neoplasia. Gastroenterology 2011; 140: 1908-1918

[3] Law R, Das A, Gregory D et al. Endoscopic resection is cost-effective compared with laparoscopic resection in the management of complex colon polyps: An economic analysis. Gastrointest Endosc 2016; 83: $1248-1257$

[4] Hassan C, Repici A, Sharma P et al. Efficacy and safety of endoscopic resection of large colorectal polyps: A systematic review and meta-analysis. Gut 2016; 65: 806-820

[5] Burgess NG, Metz A], Williams S] et al. Risk factors for intraprocedural and clinically significant delayed bleeding after wide-field endoscopic mucosal resection of large colonic lesions. Clin Gastroenterol Hepatol 2014; 12: 651-661.e3

[6] Albéniz E, Fraile M, Ibáñez B et al. A scoring system to determine risk of delayed bleeding after endoscopic mucosal resection of large colorectal lesions. Clin Gastroenterol Hepatol 2016; 14: 1140-1147

[7] Bahin FF, Rasouli KN, Byth K et al. Prediction of Clinically significant bleeding following wide-field endoscopic resection of large sessile and laterally spreading colorectal lesions: a clinical risk score. Am J Gastroenterol 2016; 111: 1115-1122

[8] Metz AJ, Bourke MJ, Moss A et al. Factors that predict bleeding following endoscopic mucosal resection of large colonic lesions. Endoscopy 2011; 43: 506-511

[9] Burgess NG, Williams S], Hourigan LF et al. A management algorithm based on delayed bleeding after wide-field endoscopic mucosal resection of large colonic lesions. Clin Gastroenterol Hepatol 2014; 12 : 1525-1533

[10] Sawhney MS, Salfiti N, Nelson DB et al. Risk factors for severe delayed postpolypectomy bleeding. Endoscopy 2008; 40: 115-119

[11] Backes Y, Schwartz MP, Ter Borg F et al. Multicentre prospective evaluation of real-time optical diagnosis of $\mathrm{T} 1$ colorectal cancer in large non-pedunculated colorectal polyps using narrow band imaging (the OPTICAL study). Gut 2019; 68: 271-279

[12] Hwang JH, Konda V, Abu Dayyeh BK et al. Endoscopic mucosal resection. Gastrointest Endosc 2015; 82: 215-226

[13] Carson JL, Triulzi DJ, Ness PM. Indications for and Adverse Effects of Red-Cell Transfusion. N Engl J Med 2017; 377: 1261-1272

[14] Dutch federation of Intensive Care (NVIC). Richtlijn Bloedtransfusie. CBO; 2011: Available from (Accessed Dec 2018): https://nvic.nl/sites/ nvic.nl/files/CBO\%20Richtlijn\%20Bloedtransfusie.pdf

[15] Pohl H, Grimm IS, Moyer MT et al. Clip closure prevents bleeding after endoscopic resection of large colon polyps in a randomized trial. Gastroenterology 2019; 157: 977-984.e3

[16] Albeniz E, Alvarez MA, Espinos JC et al. Clip closure after resection of large colorectal lesions with substantial risk of bleeding. Gastroenterology 2019; 157: 1213-1221.e4

[17] Oakland K, Jairath V, Uberoi R et al. Derivation and validation of a novel risk score for safe discharge after acute lower gastrointestinal bleeding: a modelling study. Lancet Gastroenterol Hepatol 2017; 2: 635-643

[18] Niikura R, Yasunaga H, Yamada A et al. Factors predicting adverse events associated with therapeutic colonoscopy for colorectal neoplasia: a retrospective nationwide study in Japan. Gastrointest Endosc 2016; 84: 971-982.e6

[19] Forrest JA, Finlayson ND, Shearman DJ. Endoscopy in gastrointestinal bleeding. Lancet 1974; 2: 394-397 